\title{
FELIPE II, TRENTO Y LA DIÓCESIS DE MÁLAGA
}

\author{
POR
}

\author{
DRA. MARION REDER GaDOW \\ Universidad de Málaga
}

\begin{abstract}
RESUMEN
Análisis sobre la implantación de las disposiciones emanadas del Concilio de Trento en Málaga por medio de la documentación conservada en el Archivo de la Catedral.
\end{abstract}

\section{Abstract}

Analysis on the introduction in Málaga of Council of Trento arrangements by the documentation preserved in the Cathedral Archive.

El objetivo de esta comunicación es constatar cómo el emperador Carlos y su sucesor Felipe II impulsaron la celebración del Concilio de Trento, empeño harto dificil ante la férrea oposición de los protestantes, de los monarcas franceses, del emperador Fernando y de los propios cardenales católicos alemanes que prefirieron mantener el equilibrio conseguido en la paz de Augsburgo. Tras las continuas interrupciones se lograron culminar las diferentes etapas del Concilio En él la Iglesia católica definió un elevado número de dogmas y estableció la reforma eclesiástica que tanto precisaba. Así mismo, la aplicación de las normas tridentinas en España induce a una polémica historiográfica entre los historiadores españoles y extranjeros que aún sigue vigente. En la diócesis de Málaga se fueron implantando paulatinamente los decretos emanados de Trento.

Las fuentes utilizadas para esta comunicación proceden del Archivo del Cabildo Catedralicio de Málaga. Además, este estudio se inserta en un proyecto 
de investigación que culminará en la Historia de la diócesis de Málaga durante el reinado de Felipe II.

En la Instrucción que Carlos V redactó en Augsburgo, el 19 de enero de 1548 , éste aconsejaba a su hijo, como objetivo prioritario de la monarquía hispánica, mantener la unidad católica y contribuir a la reanudación del Concilio, acatar a la Santa Sede y proveer de los beneficios eclesiásticos a personas virtuosas y capacitadas.

A pesar de estas recomendaciones paternas, Felipe, nada más acceder al trono tuvo que enfrentarse con un conflicto inesperado que aparece por la alianza del rey de Francia Enrique II y el papa Paulo IV. El emperador Carlos ya había intentado en vano impedir la elección de Juan Pedro Carafa al solio pontificio, puesto que era de origen napolitano y pertenecía a los angevinos, enemigos tradicionales de España. Pero los cardenales afectos al César no pudieron impedir su elección en el cónclave del 23 de mayo de 1555, accediendo a la silla de San Pedro con el nombre de Paulo IV. El nuevo Pontífice no vacilo en coaligarse con Enrique II y el sultán de Turquia promoviendo la invasión de Nápoles.

Para Felipe II la hostilidad de la Santa Sede constituyó un conflicto moral por lo que acudió a las Juntas de teólogos de Lovaina y de España para que determinaran qué actitud debía adoptar el rey de España al verse agredido. Entre estos teólogos se encontraba el dominico Melchor Cano. Tras intensas reuniones los asistentes llegaron a la siguiente conclusión, y así se la transmitieron al monarca: era preciso distinguir entre el Papa como jefe espiritual de la Iglesia y el Pontífice como soberano temporal, que precisaba un ejército y flotas para su defensa y contraía alianzas con otros príncipes. En este último supuesto la guerra era considerada lícita. La opinión de todos los consejeros reales no fue unánime y el arzobispo de Toledo, el cardenal Silíceo, propugnaba un compás de espera antes de atacar la Santa Sede.

Sin embargo, la táctica militar se impuso a la argumentación dialéctica y el duque de Alba, virrey de Nápoles, como buen militar y estratega no dudó en invadir los Estados Pontificios llegando hasta Ostia, en 1556. Ante la presencia del ejército espafíol Paulo IV se apresuró a solicitar una tregua, en la confianza de que las tropas francesas al mando del duque de Guisa acudieran en su auxilio. Pero éstas tuvieron que replegarse ante la superioridad del ejército español y el Pontífice tuvo que claudicar y proponer negociaciones de paz. Tratados de pacificación que el monarca Felipe no sólo autorizó, eso si exigiendo su neutralidad, sino que incluso devolvió las plazas ocupadas conquistadas al Papa y, además, el duque de Alba, en nombre del rey, debía solicitar el perdón por haber invadido los Estados Pontificios. Según algunos autores así terminó la última de las contiendas militares entre el pontífice romano como poder temporal y los

Actas del I Congreso de Historia de la Iglesia y el Mundo Hispánico

Hispania Sacra, 52 (2000) 
reyes de España, un 29 de septiembre de 1557.

Por el Tratado de Cateau-Cambresis firmado, el 3 de abril de 1559, entre el francés Enrique II y el monarca español ambos reyes se comprometieron por las primeras cláusulas a aunar sus esfuerzos para defender a la Iglesia romana y a los decretos del Concilio General.

Proposición que Felipe II renovaría personalmente ante las Cortés reunidas en Toledo al año siguiente, al afirmar que concentraría todas las fuerzas de sus Reinos en la defensa de la Iglesia Romana y en la lucha contra la herejía, y por tanto, que contribuiría a reanudar el Concilio de Trento. El Rey Prudente teme por la unidad de la Iglesia en sus Reinos. En 1558 se descubren los primeros focos de protestantismo en España. Fernando de Valdés, Inquisidor General, acomete con energía la reorganización del Santo Oficio que culmina en las Instrucciones de 1561. En 1559 tanto Paulo IV como la Inquisición española publican índices de libros prohibidos para evitar que se propague la herejía. Felipe II prohibe a los estudiantes españoles frecuentar las universidades extranjeras, salvo algunas excepciones ${ }^{1}$. Pese a estas disposiciones, el arzobispo de Toledo, Bartolomé Carranza, es procesado por la Inquisición. La reanudación del Concilio de Trento ${ }^{2}$ era una necesidad imperiosa.

Paulo IV murió en el año 1559. Felipe II dio instrucciones a su embajador en Roma para que mediara en la elección de un nuevo Pontífice que prosiguiera el Concilio y que mantuviese al orbe cristiano unido. El rey deseaba que el cardenal de los Médicis fuese elegido a toda costa, pero el embajador no pudo llevar a cabo su misión por que falleció, siendo sustituido por el agente diplomático de Milán que no dudó en quebrantar el aislamiento del concláve sobornando al cardenal Carafa para que comprase votos y se asegurara la elección deseada. En efecto, el 25 de diciembre de 1559 los deseos reales se cumplieron y fue elegido el cardenal Médicis que tomó el nombre de Pío IV. Este Pontífice estuvo acertadamente asesorado, como sucesor de San Pedro, por su sobrino Carlos Borromeo, al que nombró su secretario de Estado y cardenal cuando sólo contaba 21 affos de edad. Pese a su juventud, a San Carlos se debe la apertura del tercer período del Concilio de Trento, al que se consideró como una continuación de los acuerdos adoptados en las dos anteriores etapas. Una vez resuelto el Papa a

\footnotetext{
1 H. KAMEN, Felipe de España, Ed. Siglo XXI, Madrid, 1997, p. 83.

${ }^{2}$ M. AVLlÉs FernÁndez, «La Contrarreforma), en Manual de Historia Universal, tomo VI, Ed. Najera, Madrid, 1987, pp. 239-295. Paulo IV era partidario de la reforma de la Iglesia pero prefería reformarla personalmente prescindiendo del Concilio. Alude el autor a la labor de reforma que pretendía el pontífice Paulo IV, al mandar la reorganización de la Inquisición Pontificia tomando como ejemplo los procedimientos de la Inquisición española, al seleccionar a las personas más idóneas para los oficios eclesiásticos y al potenciar la reforma de los religiosos.
} 
convocar la reanudación del Concilio, instó a los Reyes de las naciones cristianas a que confirmaran su consentimiento; pero éste no fue inmediato y llevó su tiempo. El rey Cristianísimo Francisco II, asesorado por sus consejeros pertenecientes a los Guisa, creía que era más eficaz, para la pacificación de sus Estados, un Concilio nacional, en el que tomaran parte los teólogos calvinistas, que otro a nivel universal. El monarca francés era consciente de que Felipe II no toleraría ninguna asamblea nacional gala, por lo que difería su asentimiento exigiendo al Pontífice que convocase otro Concilio, independiente del anterior y en otra ciudad que no fuera Trento. El rey Prudente se opuso tenazmente en recuerdo del denodado esfuerzo que su padre realizó para que llegare a su término.

Aunque Pío IV convocó al Concilio por la bula del 29 de noviembre de 1560 , no indicó en la citación si se trataba de la continuación de la asamblea iniciada en Trento o de otra nueva. Ante la perplejidad del Rey y de la Iglesia española se reunión en Toledo una Junta de teólogos, bajo la presidencia del arzobispo de Sevilla, que no vislumbró con claridad si la convocatoria romana indicaba la continuación del Concilio tridentino o si se citaba para una nueva asamblea. Felipe transmitió al Papa su inquietud y que si no se aclaraba ese matiz previamente no enviaría prelados españoles a Trento. El nuncio del Papa le tranquilizó anunciándole un Breve del Pontifice en que se declararia expresamente que el Concilio convocado en la ciudad italiana era continuación de los anteriores celebrados y suspendidos en la misma urbe. La respuesta a la convocatoria de Trento fue desigual.

Felipe II tuvo que insistir a la regente francesa Catalina de Médicis para que en noviembre de 1562 llegaran a la ciudad italiana los prelados franceses: 13 obispos, 3 abades y teólogos, presididos por el cardenal de Lorena. Los príncipes alemanes se habían negado rotundamente a su celebración y participación. En Inglaterra prohibieron la entrada al portador de la invitación oficial que el Papa dirigía a la reina Isabel. Los obispos católicos alemanes tampoco acudieron alegando su temor a perturbar la paz religiosa acordada en Augsburgo en 1555 .

\section{El. Concilio de Trento}

Hacía tiempo que los fieles reclamaban una rectificación de los abusos introducidos en las jerarquias eclesiásticas y era preciso que se convocara una asamblea conciliar. A comienzos de 1523 se iniciaron los primeros tanteos diplomáticos para la convocatoria de un Concilio General, pero ésta se demoraría hasta el 13 de diciembre de 1545. Rumores de cambio de sede del Concilio, al ame-

Actas del I Congreso de Historia de la Iglesia y el Mundo Hispánico

Hispania Sacra, 52 (2000) 
nazar una epidemia a la ciudad de Trento aceleraron su clausura en septiembre de 1549.

Con motivo de la convocatoria del segundo período del Concilio (1 de mayo de 1551 al 28 de abril de 1552) por el Pontífice Julio III, el emperador Carlos ordenaba a los prelados españoles que se dispusiesen asistir al mismo. La regente Juana de Austria fue la encargada de transmitir las disposiciones reales para su cumplimiento ${ }^{3}$. Recibidas éstas en Málaga, su prelado Fray Bernardo de Manrique excusó su presencia debido a su avanzada edad y a la imposibilidad física de emprender un viaje tan distante 4 . Ahora bien, aunque Fray Bernardo Manrique no acudió personalmente a las congregaciones, ni a las sesiones de la asamblea tridentina, propuso como delegado suyo al canónigo magistral de la catedral de Málaga, al doctor don Pedro de Zumel, avalado por sus profundos conocimientos teológicos ${ }^{5}$. Mas la breve duración de esta etapa no dio tiempo a preparar su marcha. La alianza entre los protestantes y el monarca francés desencadenó la ofensiva contra el emperador sembrando la alarma entre los padres conciliares que suspendieron la asamblea en abril de 1552. Será en el tercer período (1562 a 1563), convocado por Pío IV, cuando se haga efectiva la presencia del doctor Zumel en las sesiones tridentinas, en las deliberaciones sobre temas doctrinales y de reforma de decisiva repercusión para la Iglesia ${ }^{6}$.

A medida que se aprobaban los decretos en las sesiones llegaban a las diócesis españolas las disposiciones conciliares para su cumplimiento. A la de Málaga llegaron los decretos en diciembre de 1554, con la recomendación imperial de que se pusiesen pronto en práctica. Reunido el cabildo eclesiástico capitularmente y presidido por su obispo, Fray Bernardo Manrique, recibió al corregidor, Francisco Carrillo de Guzmán, que presentó una real cédula con las normas tridentinas?.

En sus dos primeras etapas el Concilio habfa atendido prioritariamente los problemas suscitados en Alemania por el luteranismo. La asamblea conciliar constituía la pieza fundamental de un proyecto político - eclesiástico encaminado a restaurar la unidad de la Iglesia, plan trazado conjuntamente por el Papa y

\footnotetext{
3 W. SOTO ARTUÑEDO, «San Ignacio y la mujer», en Proyección, teología y Mundo actual, $\mathrm{n}^{\circ} 187$, Facultad de Teología, Granada, octubre-diciembre 1997, pp. 200-318.

4 V. GoNZALEZ SANCHEZ, «De fraile palentino a Obispo de Málaga: Fray Bernardo Manrique de Lara (1531-1563)", en Actas del III Congreso de Historia de Palencia, tomo III, Diputación Provincial, Palencia, 1995, pp. 177-207.

5 V. GONZALEZ SANCHEZ. Caracteres de la Sociedad malagueña en el siglo XVl, Diputación Provincial, Málaga, 1986.

${ }^{6}$ C. GUtiÉRREZ, S.J., Españoles en Trento, CSIC, Valladolid, 1951, p. 1011.

${ }^{7} \mathrm{~A}($ rchivo) C(abildo) C(atedralicio) de M(álaga), Legajo 1027, Actas Capitulares, tomo IX, año 1554 , fol. 233 .
} 
el emperador ${ }^{8}$. Ciertamente la Iglesia romana había hecho algunos progresos definiendo en las primeras sesiones del Concilio de Trento los dogmas que la separaban de los protestantes. Pero aún quedaba mucho por hacer?.

El 29 de noviembre de 1560 se expidió la bula de convocatoria $A d$ Ecclesiae regimen, fijando el inicio del Concilio para abril del año siguiente. La asistencia de prelados fue más numerosa que en las etapas precedentes. En la sesión de apertura se encontraban presentes 109 obispos, de origen italiano, español y portugués, ya que hasta noviembre no llegó el cardenal de Lorena acompañado de los obispos galos.

En esta tercera etapa el Concilio celebró las últimas sesiones, de la 17 a la 25. En la primera se trató la elaboración de un Índice de libros prohibidos, ya que el de Paulo IV se consideraba demasiado riguroso. En cuanto a la reforma eclesiástica se trató la obligatoriedad que tenían los obispos de residir en sus jurisdicciones episcopales para evitar la concentración de diócesis en un mismo prelado, promover la eficacia de la aplicación de las normas tridentinas en ellas y mejorar el control sobre sus eclesiásticos. A pesar de los numerosos intentos para que los obispos residieran en sus diócesis, cerca de setenta prelados italianos estaban viviendo en Roma, y esta situación era similar en otros países. Como todos los intentos para contener el absentismo episcopal, éste había fracasado hasta el momento; los delegados espantoles sostenían que la obligación que tenían los prelados de residir en sus jurisdicciones episcopales dimanaban de la voluntad divina y que por tanto el Papa no podía dispensarlos de esa obligación. Frente a éstos, los que opinaban que la obligación de residir era un precepto humano y que los españoles pretendían lesionar la potestad del Pontífice. Aunque el Concilio votó a favor de la propuesta española por lo espinoso del tema, se pospuso la resolución para otro momento.

En la sesión 20 se examinaron los puntos referentes al uso de la comunión bajo las dos especies. Se adoptaron los decretos sobre la presencia de Cristo en las dos especies eucarísticas y la necesidad de que personas dotadas con poderes necesarios, como eran los sacerdotes, pudieran consagrarlas. Por tanto, se afirma, frente al sacerdocio universal que proclaman los protestantes, la necesidad de una jerarquía en la Iglesia con poderes sagrados para consagrar.

En la sesión 21 se aprobaron las resoluciones anteriores como dogmáticas, y en lo que respecta a la reforma se reafirmaron los requisitos para que los obis-

\footnotetext{
${ }^{8}$ M. AvILÉs FERNÁNDEZ, «La Contrarreforma», en Manual de Historia Universal, tomo VI, Ed. Najera, Madrid, 1987, pp. 239-295.

'J. H. ElllotT, «El Concilio de Trento», en La Europa dividida, 1559-1598, Ed. Siglo XXI, Madrid, 1981, p. 144. 
pos confiriesen órdenes sagradas. También se trataron cuestiones disciplinares para el clero.

En la sesión 22 se prepararon decretos contra la superstición y la avaricia, así como las reformas que debían elevar la conducta de los clérigos y regular la administración de las disposiciones testamentarias o causas pías que se encomendaba a los eclesiásticos. De nuevo, resurgió el tema de la residencia de los obispos y el general de los jesuitas, Laínez, estableció que la obligatoriedad que tenían los obispos en sus diócesis era de origen divino pero la jurisdicción particular que cada obispo poseia para gobernar su jurisdicción provenía del romano Pontífice. Esta postura española se vio reforzada por el Cardenal Lorena por lo que el Papa y la curia aceptaron la proposición zanjándose definitivamente esta polémica.

En la sesión 23 se proclamaron los dogmas que afectaban al sacramento del orden, alegando que los obispos eran los sucesores de los apóstoles que habían sido ordenados por el Espíritu Santo para regir la Iglesia y de ahí su superioridad sobre los presbíteros. En los decretos de reforma se incluyó, entre otros, la creación de seminarios en cada una de las diócesis.

En la sesión 24 se reglamentó el sacramento del matrimonio para evitar los matrimonios clandestinos. Se declaraban invalidados todos aquellos que no se ajustasen a los requisitos estipulados. En el decreto de reforma se incluian los nombramientos de cardenales y obispos, la organización anual de sínodos diocesanos y la trienal de concilios provinciales. También se trató sobre la visita pastoral de la diócesis, por el obispo, la reforma de los cabildos catedrales, la provisión de las parroquias y la predicación parroquial. Por lo que respecta a la reforma de las órdenes religiosas, se dictaminó sobre la admisión, noviciado y clausura. Cuando se estaban finalizando las deliberaciones de esta sesión llegó una carta del cardenal Borromeo en la que notificaba que el Papa Pío IV se encontraba gravemente enfermo, por lo que era necesario finalizar el Concilio, ya que en caso que falleciese el Pontífice quedaban anuladas las facultades de los delegados y la misma asamblea conciliar.

Los últimos decretos conciliares que se aprobaron versaban sobre el purgatorio y se elogiaba la ayuda de los fieles a los difuntos, la veneración de las reliquias y las imágenes de los santos. Sobre cómo debian ser aplicados los decretos del Concilio en toda la Iglesia, aspectos económicos como los derechos de patronato y reducción de las fundaciones de misas.

Para finalizar se publicó otro decreto sobre indulgencias, ayunos y abstinencias, sobre la facultad que tenían los Pontífices para fijar los textos de los misales, breviarios, un catecismo oficial del concilio y un índice de libros prohibidos.

El 4 de diciembre de 1563 el legado pontificio Morone, después de la misa del Espíritu Santo, clausuró el concilio. Pío IV se recuperó de su dolencia y aún 
vivió hasta 1565.Llorca se cuestiona si verdaderamente fue tan grave la enfermedad del Papa o si solo sirvió de pretexto para adelantar su finalización, a la que Felipe II se negaba.

Después de la clausura quiso el pontífice romano que se examinasen de nuevo todos los decretos conciliares por sus teólogos, pero ya el consistorio de 26 de enero confirmó su aprobación y el 30 de junio publicó la bula Benedictus Deus et Pater ratificándolos, aunque dató su fecha en enero. La bula lleva la firma de 26 cardenales ${ }^{10}$.

Oficialmente los decretos conciliares se encontraban impresos en Roma hacía mediados de febrero de 1564 y en ellos establecieron que la Iglesia postridentina estaría totalmente subordinada a las decisiones del Papa, pues éste había emergido con un poder indemne y aumentado. Los obispos residirían a partir de entonces en sus diócesis y se fundarían seminarios en cada una de éstas para la educación del clero ${ }^{11}$.

\section{APLICACIÓN DEL CONCILIO EN LA DIÓCESIS DE MÁLAGA}

Felipe II se reunió en Barcelona con los obispos espanioles que volvían del concilio, y por ellos se informó directamente del alcance de sus canónes. El rey Católico admitió los Breves en que se contenían los decretos de Trento, aunque los sometió a examen del Consejo de Castilla.

Bernardino Llorca alude a que según el estado en que se encontraba la investigación entonces debía admitirse que Felipe II aceptó e introdujo en España y en todos los dominios, con toda amplitud y sin limitaciones, los decretos tridentinos. Recalca que la aceptación del monarca español y de todo el episcopado fue inmediata, absoluta y sin limitaciones. Ante todo se establece la obligación de los reyes de secundar las disposiciones del romano pontífice:

«Como rey obediente y verdadero hijo de la Iglesia, queriendo corresponder a la obligación en que somos y siguiendo el ejemplo de los reyes, nuestros antepasados, hemos aceptado (...) queremos que en nuestros reinos sea guardado, cumplido y ejecutado, y daremos y prestaremos para la dicha ejecución y cumplimiento, y para la conservación y defensa de lo en el ordenado.n

Se basa para esta afirmación en el texto de la real prágmatica, publicada el 12 de julio de 1564, en la que aceptaba en toda su amplitud los decretos dogmá-

${ }^{10}$ B. LLORCA, S.J., «Principio de la reforma católica. Primera etapa del Concilio de Trento» y «La reforma católica de Julio II a Pio IVm, en Historia de la Iglesia Católica, tomo III, BAC, Madrid, 1960, pp. 738-783.

il J. H. ElliotT, op. cit., p. 149.

Actas del I Congreso de Historia de la Iglesia y el Mundo Hispánico Hispania Sacra, 52 (2000) 
ticos y disciplinares emanados del concilio tridentino. Anejas se dieron una serie de disposiciones a las autoridades en orden a la admisión y puesta en práctica de la normativa conciliar. Insiste en que no se puso ninguna limitación salvo los derechos reales ${ }^{12}$.

Más cauteloso, Constantino Gutierrez afirma que Felipe II aceptó el concilio tridentino con reservas, sin perjuicio para sus reales prerrogativas o derechos. Al firmar la real prágmatica el rey Prudente aceptaba incondicionalmente las normativas tridentinas, sin limitaciones ni restricciones, incluyendo no sólo los decretos doctrinales:

\begin{abstract}
«(...) sino las muchas cosas muy santas y muy justas y muy convenientes e importantes al servicio de Dios, bien de su Iglesia y al gobiemo y policía eclesiástica que se hicieron y ordenaron en materia de reforma.,
\end{abstract}

En ese mismo año de 1564 comenzaron las promulgaciones diocesanas, (Burgos, Salamanca, Sevilla, Lérida, Cuenca y Oviedo) y en los años siguientes en las demás diócesis. También se celebraron numerosos sínodos, más de 80 en el transcurso del siglo, se fundaron seminarios como el de Granada, Burgos, Málaga...Así mismo se realizaron numerosas ediciones de los decretos tridentinos en Alcalá de Henares, Valladolid, Salamanca, Valencia, Zaragoza, Granada y Barcelona ${ }^{13}$.

Elliott resalta que una cuestión era publicar los decretos y otra hacerlos cumplir, y que aquellos que hacían referencia a la disciplina dependía de los buenos deseos de los príncipes seculares. Para este autor Felipe II, celoso de los derechos de la Corona, mostró una gran desconfianza a publicar los decretos tridentinos en España. Y que finalmente lo hizo con la expresa reserva de los derechos reales, especialmente en la cuestión de los nombramientos eclesiásticos. En esta lucha por mantener sus derechos regalistas, Felipe pudo contar con la Inquisición española y con el apoyo del episcopado, que era consciente de que sus perspectivas de promoción dependían enteramente del Rey. Señala, por ejemplo, como en el año 1572 unos breves pontificios, citando a los españoles para que compareciesen ante tribunales extranjeros en casos eclesiásticos, fueron declarados nulos y desautorizados. El rey Prudente tuvo siempre cuidado en insistir en el derecho de la Corona de revisar todas las bulas pontificias y de negar su publicación si contravenían las leyes y las costumbres de España. En este sentido, actuó para asegurarse de que los decretos tridentinos fuesen publi-

12 B. LLORCA, S.J., op. cit., p. 497.

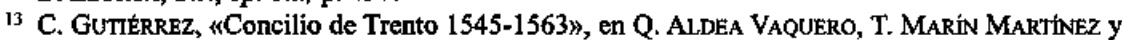
J. VIVEs GaTell, Diccionario de Historia Eclesiástica de España, CSIC, Madrid, 1972, tomo I, pp. 483-494. 
cados en sus Reinos bajo las condiciones y en las etapas que él mismo dispusiese. El agente que escogió para esta labor fue el Inquisidor General y arzobispo de Toledo Gaspar de Quiroga, más interesado en elevar el nivel del clero y en las aplicaciones de las disposiciones ceremoniales y disciplinarias de Trento que en la corriente espiritual del catolicismo español. Elliott finaliza afirmando que el control de Felipe II sobre el proceso de reforma eclesiástica en España condujo a un roce constante con el Papado, pero que estas continuas discusiones podían dañar pero nunca destruir los intereses comunes entre la Corona española y Roma, y «que inexorablemente colocaron a Felipe en el papel de paladín secular de la Iglesia» ${ }^{14}$.

Por tanto, se constata una opinión general afirmando que el monarca español aceptó las disposiciones conciliares pero se reservó aquellas conclusiones que atentaran a los privilegios de la Corona. Al mismo tiempo ordenó a los eclesiásticos que celebraran concilios provinciales para implantar aquellas decisiones que no presentaban dificultades.

Para Pedro Molas la aplicación de la reforma tridentina no se limitó a las cuestiones disciplinares sino que significó un esfuerzo por incrementar la formación cristiana del pueblo y, al mismo tiempo, por uniformar la liturgia basada en el breviario y misal romano; la difusión de lo que se llamó el «nuevo rezado" ${ }^{15}$. Después de Trento se incrementó el esfuerzo de catequesis y de predicación, por medio de las órdenes religiosas ${ }^{16}$.

En Málaga se retrasó la convocatoria de un sínodo por el fallecimiento del obispo Fray Bernardo Manrique, acaecido el 25 de septiembre de 1564. Era preciso que otro prelado ocupase la mitra malagueña. El nombramiento recayó en Francisco Blanco de Salcedo, obispo de Orense, a primeros de $1565^{17}$. La elección real de Felipe II fue muy meditada ya que el conocimiento entre ambos se remontaba años atrás. Siendo aún príncipe, el Rey Prudente distinguió a Blanco Salcedo como teólogo de Cámara y, cuando se convocó la tercera etapa del concilio de Trento, fue designado por el Monarca como miembro de la representación española, teniendo una destacada intervención en las diferentes

\footnotetext{
14 J. H. ElLIOTT, op. cit., p. 163.

15 Campos y FernándeZ De SEvilLA, F.D., «Felipe II, el Monasterio de El Escorial y el Nuevo Rezado (1573-1598), Felipe II y su época, Estudios Superiores de El Escorial, San Lorenzo, 1998, pp.

16 P. Molas Ribalta, Manual de Historia de España. Edad Moderna (1474-1808), Espasa Calpe, Madrid, 1996, p. 201.

17 M. $^{a}$ REDER GADOW, «Un palentino en la mitra malagueña: Las Constituciones sinodales del obispo Blanco de Salcedo (1561-1574)", en Actas del III Congreso de Historia de Palencia, tomo III, Diputación Provincial, Palencia, 1995, pp. 105-119.
} 505-548.

Actas del I Congreso de Historia de la Iglesia y el Mundo Hispánico Hispania Sacra, 52 (2000) 
sesiones, en las que se plantearon cuestiones como la misa como sacrificio, la defensa del derecho divino de los obispos y el de la residencia en sus respectivas sedes, la necesidad del sacerdocio, la reglamentación de los matrimonios, etc. A su vuelta de Roma Felipe II le propone, el 13 de abril de 1565, para el obispado de Málaga. Propuesta confirmada por Pío IV extendiéndose las bulas en Roma el 4 de junio de ese mismo año. Muy pronto llegó a Málaga el electo obispo ya que en el cabildo del día 16 del mismo mes se estudió el modo de recibirlo ${ }^{18}$. Entre los primeros actos de gobierno figuró una amplia visita pastoral, siguiendo la normativa tridentina, para conocer la situación y necesidades de las iglesias urbanas y rurales de su diócesis.

El 22 de junio del año 1572 convocó un sínodo para el día de san Martín con la finalidad de implantar los cánones y disposiciones tridentinas, siendo el primero en observarlas. Fueron designados dos dignidades y dos canónigos como diputados para gestionar el protocolo y redactar los puntos esenciales. Los nombramientos recayeron en el arcediano de Málaga y en el tesorero, así como los canónigos Bartolomé de Baena y Diego González Quintero. Se estableció la compensación económica por la dedicación a la preparación del sínodo. Días previos a la celebración de la asamblea diocesana se reunió el Cabildo para aclarar con su Prelado algunos detalles. Por ejemplo:

- «Que no se entienda con los prebendados de esta Iglesia el acompañamiento al Santo Sacramento de la Eucaristía cantando el tantum ergo

- Que se pida declaración del capínulo que trata de acompafiar a los clérigos las mujeres que no entienda de camino

- Que se muestre con su Sefionía donde hubiere pena de excomunión

- Que se declare el capitulo de los monasterios adonde dice no vayan diga no frecuenten

- Que se pida declaración del capítulo que trata que no puedan rezar por horas, ni por breviarios, entretanto que se dizen las horas o misas cantadas (...)"

Los Estatutos de don Francisco Salcedo tocaron aquellos artículos que fueron reformados en las últimas sesiones Conciliares y en las que el obispo malacitano intervino activamente. Entre ellas cabe destacar:

1. El derecho divino de los obispos y la obligación que tenían de residir en sus diócesis

2. El uso de la comunión, afirmando la presencia de Cristo en las especies eucaristicas.

${ }^{18}$ ACCM, Leg. 1027, Actas Capitulares n.. ${ }^{\circ} 11$, fol. 183. 
3. Las condiciones para que los obispos confirieran las órdenes sagradas.

4. Los decretos de reforma de la conducta de los clérigos decretos en torno a la fijación de disposiciones testamentarias y de la administración de los bienes que se les encomendaban (causas u obras pías).

5. Dogmas referentes al Sacramento del Orden, regulando la formación de los clérigos, disponiendo la creación de seminarios en cada diócesis

6. Se reglamentó el sacramento del matrimonio, la forma en que debía celebrarse el matrimonio católico y se rechazaron los matrimonios clandestinos.

7. Decreto de organización de la Iglesia regulando el nombramiento y los deberes del cargo de cardenales y obispos, la organización anual de sínodos diocesanos y el trienal de concilios provinciales, la visita de las diócesis por el obispo, la reforma de los cabildos catedrales, la provisión de las parroquias y la predicación parroquial. También se trató el tema de las órdenes, sobre la admisión, noviciado y la tonsura.

8. En la última sesión aprobaron los últimos decretos Conciliares sobre el purgatorio, sobre la veneración de las reliquias y las imágenes de los santos y en torno a la inmunidad eclesiástica.

9. Finalmente, se publicó un decreto sobre las indulgencias, sobre ayunos y abstinencia que obligatoriamente debían observar los católicos en fechas determinadas.

Las Constituciones emanadas del mismo fueron impresas en Granada al affo siguiente, 1573. Éstas se mantuvieron vigentes hasta el 21 de noviembre de 1671, año en que el obispo malacitano, Fray Alonso de Santo Tomás, convocó un nuevo sínodo ampliando los títulos y capítulos que los nuevos tiempos demandaban.

Otras noticias sobre la aplicación paulatina de las normas tridentinas aparecen desgranadas en las actas capitulares. En los últimos días de noviembre de 1568 el cabildo catedralicio acuerda escribir al monarca para que suprimiera la canonjía del Santo Oficio, tal como se ordenó en Trento y que en la Iglesia malacitana aún se conservaba. Petición que se vuelve a reiterar en el año 1570: «atento a que no la tiene en ninguna Iglesia del Reino de Granada». Además se pide que se provea en la persona del doctor Vilches Pacheco, racionero de su cabildo.

También en el año 1569 se convoca un Concilio provincial en Granada para tratar sobre el subsidio, levantamiento de moriscos y perjuicios causados a las iglesias. Se nombró al arcediano de Málaga, Fernando de Puebla, como delegado recomendándole que fuera protegido por la inseguridad del momento. A su

Actas del I Congreso de Historia de la Iglesia y el Mundo Hispánico

Hispania Sacra, 52 (2000) 
regreso dio cuenta al cabildo de los asuntos tratados junto con los capitulos definidos en el mismo.

Por lo que atañe a los beneficios, se ordenó que dentro del año debían ordenarse en ese mismo año o serían castigados. El arcediano de Vélez instó: «para cumplir lo decretado y mandado por el santo concilio tridentino", al realizar su juramento. Presente se hallaba el arcediano de Málaga, como presidente, y dos capitulares como testigos, que recibieron el juramento del doctor Jorge de Padilla, de rodillas y con las manos sobre el misal, acatando «todo aquello que ordenaba la Iglesia de Roma». Ratificaba el acto el notario, y secretario del cabildo catedralicio, Bartolomé Domínguez.

Así mismo, en cabildo de 30 de junio de 1569 se propuso que tal como se lleva a cabo en otras ciudades se solemnizara en Málaga la fiestas de sus patrones, el 18 de junio. Unánimemente se acordó que el día de los Santos Patronos malacitanos, San Ciriaco y Santa Paula, acompanarían al Regimiento municipal en la solemne procesión que desde la Iglesia Catedral se dirigía a la parroquia de su advocación "como antes se solía hacer»" ${ }^{19}$.

Será el obispo Luis García de Haro y Sotomayor el que iniciará los trámites para fundar el Seminario. En el año 1587 dirige un memorial al monarca para que, como patrono de la Iglesia malacitana, procediese a su fundación y le señalase los recursos de su real Patronato para proveerlo ${ }^{20}$. Pero el proyecto se posterga ante la presencia de varias epidemias de peste en la ciudad y en su diócesis. Años después, el 8 de octubre de 1597, el príncipe Carlos expedía, en nombre de su padre enfermo, en El Escorial la real cédula de erección del Seminario malacitano. En este documento Felipe II hace referencia a la diligencia del obispo García de Haro para la fundación del Seminario, según la asamblea tridentina. La real cédula se recibe en Málaga el 14 de enero de 1598, García de Haro había muerto unos meses antes sin tener conocimiento de la real cédula de fundación del Seminario. Será el nuevo obispo Tomás de Borja, quien culmine el proyecto del prelado García de Haro durante su prelatura ${ }^{21}$.

El concilio de Trento sentó las bases de una teología que definía con precisión las cuestiones fundamentales referentes a la Sagrada Escritura, a la gracia. $\mathrm{Y}$ al tiempo que se definían las cuestiones dogmáticas se habian dictado medidas disciplinares de reforma de la Iglesia. 